\title{
International Conference on Nuclear Knowledge Management: Strategies, Information Management and Human Resource Development
}

\author{
7-10 September 2004, Saclay, France
}

\author{
Organized by \\ International Atomic Energy Agency (IAEA) \\ co-organized and hosted by \\ Government of France through the Commissariat de l'Energie Atomique (CEA) \\ in co-operation with \\ European Commission (EC) \\ OECD Nuclear Energy Agency (OECD/NEA) \\ European Atomic Forum (FORATOM) \\ Japan Atomic Industrial Forum (JAIF) \\ World Council of Nuclear Workers (WONUC) \\ World Nuclear University (WNU) \\ European Association of Information Services (EUSIDIC)
}

\section{Background}

Like any highly technical endeavour, the use of nuclear technology relies heavily on the accumulation of knowledge. This includes technical information in the form of scientific research, engineering analysis, design documentation, operational data, maintenance records, regulatory reviews and other documents and data. It also includes knowledge embodied in people - e.g., scientists, engineers and technicians and human resources.

In recent years, a number of trends have drawn attention to the need for better management of nuclear knowledge. Depending on region and country, they include an ageing workforce, declining student enrolment figures, the risk of losing nuclear knowledge accumulated in the past, the need for capacity building and transfer of knowledge and recognition of achieving added value through knowledge sharing and networking. 
"Whether or not nuclear power witnesses an expansion in the coming decades, it is essential that we preserve nuclear scientific and technical competence for the safe operation of existing facilities and applications. Effective management of nuclear knowledge should include succession planning for the nuclear work force, the maintenance of the 'nuclear safety case' for operational reactors, and retention of the nuclear knowledge accumulated over the past six decades.

This is a growing concern for many of our Member States, and is a topic that relates to all areas of Agency activity. [...] A substantial area of Agency activity involves assisting Member States with capacity building and human resources development - through education programmes, hands on training, and knowledge transfer - in ways best suited to their desired uses of nuclear technology."

In 2002, the annual meeting of the National Liaison Officers of the International Nuclear Information System (INIS) approved to hold their 2004 meeting in the form of a conference dedicated to nuclear knowledge and information management.

In 2002, the IAEA General Conference adopted a new resolution on "Nuclear Knowledge", reiterated in 2003, emphasizing the importance of these issues, calling for increased awareness and inviting both the Agency and Member States to strengthen their activities and efforts. The conference is organized in response to the recommendations from the INIS annual meeting of Liaison Officers and to the General Conference resolution.

\section{Objectives}

The objective of this conference is to reach a clear and common understanding of issues related to nuclear knowledge management for sustaining knowledge and expertise in nuclear science and technology.

The conference will provide a forum for professionals and decision makers in the nuclear sector, comprising industry, governments and academia as well as professionals in the knowledge management and information technology sectors

- to exchange information and share experience on nuclear knowledge management, comprising strategies, information management and human resource development;

- to identify lessons learned and to embark on the development of new initiatives and concepts for nuclear knowledge management in IAEA Member States;

- for the INIS session, to discuss the present status and future developments of INIS.

\section{Thematic scope}

The conference will comprise the following topical sessions:

Session 1: Nuclear knowledge management - policies and strategies

- Policies and strategies for managing nuclear knowledge, both in developing and in developed countries, arising in operating installations, for achieving sustainable development in both nuclear energy and nuclear applications, for maintaining high safety standards and for securing a base for future $R \& D$ and innovations.

- The session may also include relevant examples from managing non-nuclear knowledge.

\footnotetext{
${ }^{1}$ IAEA Director General Dr. Mohamed ElBaradei, Statement to the forty-seventh regular session of the IAEA General Conference 2003 .
} 
Session 2: Managing nuclear information - policies and strategies

- Approaches and concepts for managing nuclear information on either global, regional, national or institutional or corporate levels;

- Nuclear information and nuclear data management systems, internet based concepts and information portals;

- Information technology (IT) concepts and tools and related strategies.

Session 3: Managing nuclear information - case studies

- Case studies and on-going or planned projects related to managing nuclear information;

- Issues related to the need to preserve information and knowledge in the nuclear sector;

- Special focus will be given to case studies and projects on the preservation of nuclear information and knowledge.

Session 4: Human resources for the nuclear sector

- The "human resource pipeline" including studies, approaches, assessments and strategies for both the demand and the supply side of human resources in the nuclear sector;

- The "supply side" of manpower comprises nuclear education, higher education and professional training, including university curricula, training approaches, and national support plans for human resources in the nuclear sector;

- The "demand side" of manpower comprises the need for human resources, arising in industry, for capacity building in developing countries, for innovation and to sustain a knowledge base for future R\&D.

\section{Session 5: Networking nuclear education and training}

- Studies and projects related to networking institutions in nuclear education and training, e.g., curriculum harmonization and mutual recognition of degrees, university networks, student and teacher's mobility programmes and collaborative approaches for education and training;

- Special attention will be given to papers featuring best practice and lessons learned with an aim to facilitate the transfer of experience to new initiatives.

Special sessions on

- the International Nuclear Information System (INIS);

- "Young Generation in the Nuclear Sector";

- "Innovation and Nuclear Knowledge".

\section{Expenditures}

No registration fee is charged to participants. As a general rule, the IAEA does not pay the cost of attendance, i.e. travel and living expenses, of participants. However, limited funds are available to help meet the cost of attendance of selected specialists mainly from developing countries with low economic resources. Travel grants will be awarded only to authors of accepted papers. Generally, not more than one grant will be awarded to any one country.

Applications that do not comply with those conditions cannot be considered. The grants awarded will be in the form of lump sums that usually cover only part of the cost of attendance.

\section{Conference proceedings}

Full proceedings of the conference will be published shortly after the conference. 
Working language

The working language of the Conference will be English. All communications, synopses, abstracts and papers must be sent in English.

\section{Distribution of documents}

A preliminary programme of the conference will be sent to the participants in advance of the conference. The final programme and the book of extended synopses will be distributed on registration.

\section{Accommodation}

Detailed information on accommodation and other information of interest will be sent to all designated participants well in advance of the meeting and will also be available on the conference webpage.

Visas

Designated participants who require a visa to enter France should submit the necessary application(s) to the nearest diplomatic or consular representative of France as early as possible. E-mail: official.mail@iaea.org

\section{Scientific Secretariat (IAEA)}

The address of the Secretariat is:

International Atomic Energy Agency

Conference IAEA-CN-123

Vienna International Centre

Wagramer Strasse 5

P.O. Box 100

A-1400 Vienna, Austria

Tel.: +43 12600 plus extension

E-mail: n.pereppadan@iaea.org

The Scientific Secretaries of the Conference are:

Mr. H.S. Cherif

Department of Management

Tel.: +4312600 21117

E-mail: H.S.Cherif@iaea.org

Mr. P.J. Gowin

Department of Nuclear Energy

Tel.: +431260022811

E-mail: P.Gowin@iaea.org

Mr. Y. Yanev

Department of Nuclear Energy

Tel.: +4312600 22887

E-mail: Y.Yanev@iaea.org 


\section{Secretarial support:}

Mr. Nixon Pereppadan

Tel.: +431260022836

E-mail: n.pereppadan@iaea.org

\section{Conference organization:}

Ms. Mariel Solarik

Conference Service Section

Tel.: +431260021321

E-mail: M.Solarik-Leahy@iaea.org

\section{Local organizer (CEA, France)}

Mr. Bruno Gillet

CEA Nuclear Energy Division

Batiment 212

91191 Gif-sur-Yvette Cedex

France

Tel.: +33269085355

Fax: +33 169085795

E-mail: bruno.gillet@cea.fr

\section{Channels of communication}

The Participation Form (Form A) and the Form for the Submission of a Paper (Form B), together with two copies of each synopsis, and, if applicable, the Grant Application Form (Form C), should be sent to the competent national authority (Ministry of Foreign Affairs or national atomic energy authority) for official transmission to the IAEA.

Subsequent correspondence on scientific matters should be sent to the Scientific Secretaries and correspondence on administrative matters to the IAEA Conference Service Section.

Conference web page: http://www-pub.iaea.org/MTCD/meetings/meetings.asp 